\title{
"A COMPARISON BETWEEN SUGAR CONSUMPTION AND ETHANOL PRODUCTION IN WORT BY IMMOBILIZED SACCHAROMYCES CEREVISIAE, SACCHAROMYCES LUDWIGII AND SACCHAROMYCES ROUXII ON BREWER'S SPENT GRAIN"
}

\author{
Mohammadi, Aniseh; Razavi, Seyyed Hadi ; Mousavi, Seyyed Mohammad; Rezaei, Karamatollah
}

Department of Food Science, Engineering and Technology, Faculty of Agricultural Engineering and Technology, University of Tehran, Karaj, Iran, P.O. Box: 31887-77871.

Submitted: September 16, 2009; Returned to authors for corrections: June 23, 2010; Approved: January 13, 2011.

\begin{abstract}
The immobilization of Saccharomyces cerevisiae DSM 70424, Saccharomyces ludwigii DSM 3447 and Saccharomyces rouxii DSM 2531 on brewer's spent grain and then ethanol production and sugar consumption of these immobilized yeasts were investigated. The aim of this study was to investigate the abilities of these three immobilized yeasts for producing alcohol for brewing at two temperatures (7 and 12 ${ }^{\circ} \mathrm{C}$ ) using two different sugar levels (one at original level supplied in the brewery and one with $2.5 \%(\mathrm{w} / \mathrm{v})$, added glucose to the wort).

Increasing both parameters resulted in higher alcohol production by all the yeasts studied. At $7{ }^{\circ} \mathrm{C}$ and with original wort density the ethanol content at the end of fermentation was $2.7 \%$ (v/v) for S. cerevisiae, $1.7 \%$ for S. ludwigii and $2.0 \%$ for S. rouxii. After the addition of $2.5 \%(\mathrm{w} / \mathrm{v})$ glucose at the same temperature (7 ${ }^{\circ} \mathrm{C}$ ), the alcohol production was increased to 4.1, 2.8 and 4.1\%, respectively. Similar improvements were observed when the fermentation was carried out at $12{ }^{\circ} \mathrm{C}$ with/without the addition of glucose to the wort. However, temperature indicated greater influence on $S$. ludwigii than did on S. rouxii and S. cerevisiae. The immobilization as carried out in this study impacted both $S$. ludwigii and S. rouxii in a way that they could consume maltose under certain conditions.
\end{abstract}

Key words: Brewer's spent grain, Fermentation, Immobilization, Saccharomyces cerevisiae, Saccharomyces ludwigii, Saccharomyces rouxii.

\section{INTRODUCTION}

Cell immobilization in alcoholic fermentation has been paid exclusive attention during the past three decades (2). This is due to the numerous technological and economical advantages involved with the immobilized yeast cells when compared with free cell systems $(2,3,7,8)$. Such consideration can provide the possibility of continuous processings, improve the cell stability and reduce the costs associated with the recycling and downstream processing. Fermentation efficiency of the cells as well as their resistance against shear forces can also be improved $(8,13)$. However, the support used for the

*Corresponding Author. Mailing address: Department of Food Science, Engineering and Technology, Faculty of Agricultural Engineering and Technology, University of Tehran, Karaj, Iran. P.O. Box: 31887-77871.; Tel.: +98-261-2248804.; E-mail: Srazavi@ut.ac.ir 
immobilization of the yeast cells must be available at an affordable cost and should not interfere with the aroma/taste of the product. The support should also provide convenient immobilization, high cell loading, low mass transfer limitations, stability, rigidity, possibility to regenerate and sterilize and the flexibility for reactor designs and finally, it has to be food grade $(2,4,8,9,10)$. Taking into the account these requirements and trying to meet a low price substrate, the spent grains, a brewing by-product with considerable cellulose content, was studied as a potential carrier for yeast immobilization $(1,2,4,9,10)$.

Yeast immobilization has also shown an impact on the cellular metabolism $(8,14,21,22)$. Yeast is the most important microorganism for producing fermented beverages (12). During brewing, as a result of the fermentation a sweet and rather bland drink (wort) changes to one that has delighted humankind for millennia (beer) (11).

The fundamental physiological characteristic of beer- and wine-brewing yeasts is their ability to produce two-carbon $\left(\mathrm{C}_{2}\right)$ components, in particular ethanol from carbohydrates, which are usually six-carbon $\left(\mathrm{C}_{6}\right)$ molecules such as glucose, without completely oxidizing them to $\mathrm{CO}_{2}$, even in the presence of oxygen (15).

Saccharomyces cerevisiae is the principal yeast used for beer production. Microscopically, this yeast appears as globose or ovoidal cells with multilateral budding that ferments glucose, sucrose, and raffinose and assimilate glucose, sucrose, maltose and raffinose (6).

Saccharomyces ludwigii appears as lemon-shaped cells (6, 18, 23) with blunt tips, sausage-shaped, curved, or elongated with a swelling in the middle. At times, cells are single or appear in pairs or groups of three (6). Asexual reproduction is by bipolar budding $(6,23)$. Glucose, sucrose, and raffinose are among the sugars that can be fermented by this microorganism while it can assimilate glucose, sucrose, raffinose and glycerol (6).

Saccharomyces rouxii is one of the most osmotolerant yeasts $(16,17)$ closely related to $S$. cerevisiae (16). S. rouxii microscopically appears as spherical, ellipsoidal or elongated cells with multilateral budding. This yeast can ferment glucose and maltose and assimilate glucose, trehalose, glycerol, dmannitol, and d-glucitol (6).

Immobilization of $S$. cerevisiae has already been repeated in the literature $(2,3,4,9,10,20,21,22)$ but no immobilization was found for the other two species. Therefore, the aim of this study was to immobilize two brewer yeast species, i.e., S. ludwigii and S. rouxii and compare their fermentation properties with those of S. cerevisiae. Then, the effects of temperature $\left(7\right.$ and $12^{\circ} \mathrm{C}$ ) and sugar level (one with the original condition supplied in brewery and one with $2.5 \%$ (w/v) glucose added to the wort), on the sugar consumption and ethanol production by the three immobilized yeasts $(S$. cerevisiae, S. ludwigii and $S$. rouxii) will be investigated.

\section{MATERIALS AND METHODS}

\section{Yeast strains and fermentation media}

S. cerevisiae DSM 70424 as well as S. ludwigii DSM 3447 and $S$. rouxii DSM 2531 were supplied by DSMZ (Deutsche Sammlung von Mikroorganismen und Zelkulturen, Braunschweig, Germany). Yeasts were cultivated on YM-agar (Yeast Mold-agar) containing $3 \mathrm{~g} / \mathrm{l}$ yeast extract, $3 \mathrm{~g} / \mathrm{l}$ malt extract, $5 \mathrm{~g} / 1$ soybean peptone, $10 \mathrm{~g} / 1$ glucose and $15 \mathrm{~g} / \mathrm{l}$ agar for two days at $28^{\circ} \mathrm{C}$ and then inoculated in YM-broth (Yeast Mold-broth) medium containing the above compounds without agar and allowed to grow for $24 \mathrm{~h}$ under aerobic conditions on a rotary shaker $(150 \mathrm{rpm})$. This medium with the above composition was also used for the immobilization but the respective amount of glucose was $100 \mathrm{~g} / \mathrm{l}$. The wort was obtained from Behnoosh Brewery (Tehran, Iran) and then it was hopped and filtered. The $\mathrm{pH}$ of wort was 4.87 and the initial density was $6.5^{\circ} \mathrm{P}$. All media were sterilized at $121^{\circ} \mathrm{C}$ for $15 \mathrm{~min}$.

\section{Immobilization}

Brewer's spent grains (BSG) were obtained from Behnoosh Brewery (Tehran, Iran) and used after delignification. 
Delignification was performed according to Kopsahelis et al. $(9,10)$. Six hundred grams of BSG were mixed with $1600 \mathrm{ml}$ solution of $1 \%(\mathrm{w} / \mathrm{v}) \mathrm{NaOH}$, and boiled for about $3 \mathrm{~h}$. Then, the delignified BSG (DBSG) were thoroughly washed with water, drained and sterilized at $121{ }^{\circ} \mathrm{C}$ for $20 \mathrm{~min}$.

Cell immobilization on DBSG was carried out by mixing $10^{12}$ cells $/ \mathrm{ml}$ from each of $S$. cerevisiae, S. ludwigii or S. rouxii grown in $300 \mathrm{ml} \mathrm{YM}$ media for $24 \mathrm{~h}$ with $100 \mathrm{ml}$ of this media consisting of $400 \mathrm{~g} / \mathrm{l}$ glucose monohydrate and with $100 \mathrm{~g}$ of sterilized DBSG and allowed to ferment for $24 \mathrm{~h}$ at $25^{\circ} \mathrm{C}$. The supernatant liquid was decanted and the support was washed twice with $200 \mathrm{ml}$ of the sterilized wort. The prepared biocatalysts were used directly in the fermentation of the wort.

\section{Fermentation}

Fermentation was carried out using $100 \mathrm{~g}$ of the immobilized yeast species mixed with $200 \mathrm{ml}$ of the sterilized wort. The original wort density when obtained from brewery was $6.5^{\circ} \mathrm{P}$. After the addition of glucose, the wort density reached to $9{ }^{\circ} \mathrm{P}$. To study the effect of sugar addition on alcohol production both types of wort were fermented at two temperatures of 7 and $12{ }^{\circ} \mathrm{C}$.

Fermentation was continued until the density of the wort reached to that of commercial products (i.e., 1.8- $\left.4.4^{\circ} \mathrm{P}\right)(10)$. Total fermentation time was $235 \mathrm{~h}$ when carried out at $7^{\circ} \mathrm{C}$ and $168 \mathrm{~h}$ when carried out at $12{ }^{\circ} \mathrm{C}$.

\section{Assays}

Fermentation progresses were monitored by recording the reduction of the density of the fermenting liquids at various time intervals. Density $\left({ }^{\circ} \mathrm{P}\right)$ was analyzed using a Digital Beer Analyzer (Anton Paar, Graz, Austria). pH was measured using a pH meter (Consort C860, Belgium). Sugar consumption and ethanol production were determined using an HPLC (Knauer, Germany) consisting of a K-3800 autosampler, a Eurokat $\mathrm{H}$ $(300 \times 8 \mathrm{~mm} \times 10 \mu \mathrm{m})$ column, a K-1001 pump and a K-2301 RI detector. Water (distilled and filtered) at a flow of $0.7 \mathrm{ml} / \mathrm{min}$ was used as the mobile phase. Column temperature was set at $60{ }^{\circ} \mathrm{C}$. Samples were filtered through $0.2 \mu \mathrm{m}$ membrane filters and $40 \mu 1$ was injected for each analysis.

\section{Scanning electron microscopy}

Pieces of the immobilized biocatalysts (yeast cells immobilized on DBSG) were washed with deionized water and dried overnight at $30^{\circ} \mathrm{C}$. The samples were coated with gold in a Bal-Tec SCD 005 Sputter Coater for 3 min and examined in a Philips model XL30 (Holland) scanning electron microscope.

\section{Statistical analysis}

All treatments were carried out in triplicate and the mean values are presented. The means were compared by Tukey's HSD (honestly significant difference) procedure $(p<0.05)$ by “SAS JMP Statistical Discovery 7.01” software.

\section{RESULTS AND DISCUSSION}

\section{Immobilization and fermentation}

Immobilization on DBSG was carried out and fermentation of the wort, using the immobilized yeast strains (S. cerevisiae, S. ludwigii and S. rouxii) was studied. The suitability of these biocatalysts was discovered by studying repeated fermentation batches. S. cerevisiae and S. ludwigii fermented all batches of wort with equal rates but $S$. rouxii's rate of fermentation changed through the fourth batch, but it was constant after that. Therefore, the fifth batch of fermentation was used for all of the yeasts studied.

Cell immobilization on DBSG and suitability of the immobilized biocatalysts for fermentation was confirmed also with scanning electron microscopy showing yeast cells attached on the porous surface (Figure 1). For this study wort was mixed with biocatalysts and allowed to ferment at two temperatures and two density levels. Sampling was carried out at various time intervals. 

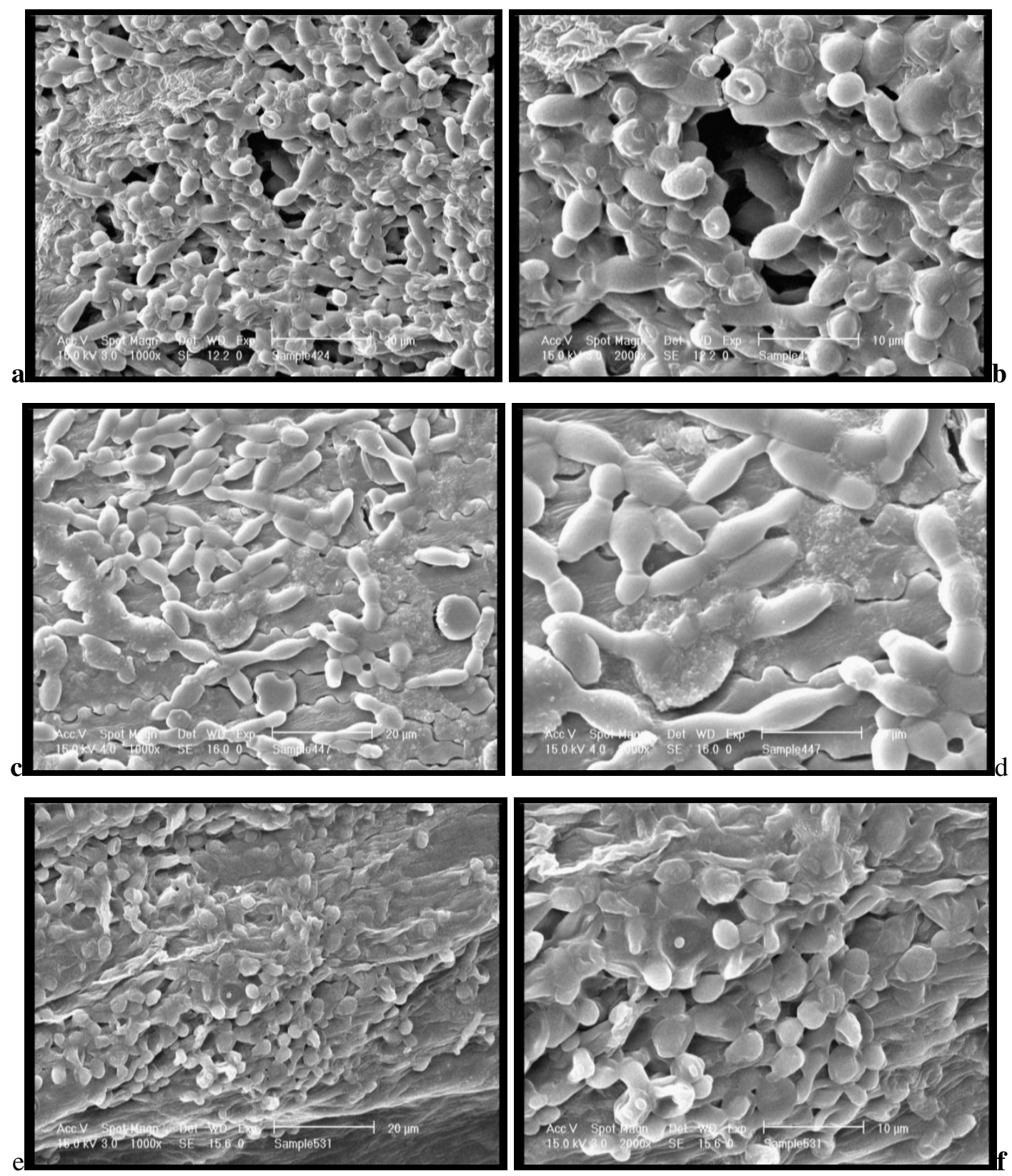

Figure 1. Scanning electron micrographs showing yeast cells immobilized on delignified brewer's spent grains, (a) S. cerevisiae, at $\times 650$, (b) S. cerevisiae, at $\times 1300$, (c) S. ludwigii, at $\times 650$, (d) S. ludwigii, at $\times 1300$, (e) S. rouxii, at $\times 650$ and (f) S. rouxii, at $\times 1300$ magnification levels.

Effect of yeast strain and glucose addition on the ethanol production

The results of fermentation of the wort at two density levels $\left(6.5\right.$ and $\left.9{ }^{\circ} \mathrm{P}\right)$ and two temperatures $\left(7\right.$ and $\left.12{ }^{\circ} \mathrm{C}\right)$ by the three yeast strains ( $S$. serevisiae, $S$.ludwigii and $S$. rouxii) are presented in Tables 1- 4. Table 1 shows the ethanol productions at $7{ }^{\circ} \mathrm{C}$ when the original wort of Behnoosh brewery was used. The final ethanol concentration was $2.7 \%$ 
(v/v) for S. cerevisiae, $1.7 \%$ for $S$. ludwigii and $2.0 \%$ for $S$. rouxii. When $2.5 \%(\mathrm{w} / \mathrm{v})$ glucose was added (Table 2$)$, the final ethanol concentration were improved to $4.1 \%$ (v/v) for $S$. cerevisiae, $2.8 \%$ for $S$. ludwigii and $4.1 \%$ for S. rouxii.

At the regular wort density, S. cerevisiae performed better than the other two strains. However, once the density changed to $9.0^{\circ} \mathrm{P}, S$. rouxii and $S$. cerevisiae did not show any differences in their alcohol production properties, but they still performed better than $S$. ludwigii.

At $12{ }^{\circ} \mathrm{C}$ and when the original wort was used, $S$. cerevisiae showed little improvement in the alcohol production level when compared to that at $7{ }^{\circ} \mathrm{C}$ (Table 3). However, major improvements were observed for the other two immobilized yeast strains at the higher temperature. Addition of $2.5 \%(\mathrm{w} / \mathrm{v})$ glucose at $12{ }^{\circ} \mathrm{C}$ resulted in further increase in the alcohol production for all three strains (Table 4).

According to the results of this study, glucose addition has influenced the ethanol production at both fermentation temperatures. Overall ethanol productions for all the treatments of this study are compared against each other in Table 5. The same discussions presented earlier in this article are applicable to justify the data presented in this Table.

Table 1. Changes in the fermentation parameters of the wort with $6.5^{\circ} \mathrm{P}$ density (i.e., original density) at $7{ }^{\circ} \mathrm{C}$ during $235 \mathrm{~h}$ of incubation.

\begin{tabular}{|c|c|c|c|c|c|c|c|c|c|}
\hline \multirow[b]{2}{*}{$\begin{array}{l}\text { Time } \\
\text { (h) }\end{array}$} & \multicolumn{3}{|c|}{ S. cerevisiae } & \multicolumn{3}{|c|}{ S. rouxii } & \multicolumn{3}{|c|}{ S. ludwigii } \\
\hline & $\begin{array}{c}\text { Density } \\
\left({ }^{\circ} \mathbf{P}\right)\end{array}$ & $\begin{array}{l}\text { Ethanol } \\
(\%, \mathrm{v} / \mathrm{v})\end{array}$ & pH & $\begin{array}{c}\text { Density } \\
\left({ }^{\circ} \mathbf{P}\right)\end{array}$ & $\begin{array}{c}\text { Ethanol } \\
(\%, \mathrm{v} / \mathrm{v})\end{array}$ & pH & $\begin{array}{c}\overline{\text { Density }} \\
\left({ }^{\circ} \mathbf{P}\right)\end{array}$ & $\begin{array}{l}\text { Ethanol } \\
(\%, v / v)\end{array}$ & pH \\
\hline 0 & $6.5 \pm 0.0$ & $0.0 \pm 0.00$ & $4.87 \pm 0.00$ & $6.5 \pm 0.0$ & $0.0 \pm 0.00$ & $4.87 \pm 0.00$ & $6.5 \pm 0.0$ & $0.0 \pm 0.00$ & $4.87 \pm 0.00$ \\
\hline 24 & $4.2 \pm 0.2$ & $1.4 \pm 0.08$ & $3.91 \pm 0.05$ & $4.4 \pm 0.4$ & $1.0 \pm 0.15$ & $3.90 \pm 0.07$ & $4.7 \pm 0.3$ & $0.7 \pm 0.05$ & $3.87 \pm 0.02$ \\
\hline 48 & $3.6 \pm 0.3$ & $1.6 \pm 0.11$ & $3.71 \pm 0.04$ & $4.0 \pm 0.5$ & $1.8 \pm 0.20$ & $3.70 \pm 0.08$ & $4.5 \pm 0.2$ & $1.2 \pm 0.04$ & $3.69 \pm 0.05$ \\
\hline 96 & $2.7 \pm 0.4$ & $1.9 \pm 0.15$ & $3.63 \pm 0.08$ & $2.9 \pm 0.5$ & $1.4 \pm 0.25$ & $3.62 \pm 0.10$ & $4.2 \pm 0.1$ & $1.4 \pm 0.08$ & $3.62 \pm 0.03$ \\
\hline 150 & $2.6 \pm 0.4$ & $2.4 \pm 0.15$ & $3.55 \pm 0.11$ & $2.6 \pm 0.3$ & $2.3 \pm 0.37$ & $3.55 \pm 0.09$ & $4.0 \pm 0.1$ & $1.5 \pm 0.05$ & $3.53 \pm 0.02$ \\
\hline 235 & $2.5 \pm 0.1$ & $2.7 \pm 0.07$ & $3.49 \pm 0.04$ & $2.5 \pm 0.2$ & $2.0 \pm 0.51$ & $3.50 \pm 0.05$ & $3.2 \pm 0.2$ & $1.7 \pm 0.06$ & $3.47 \pm 0.02$ \\
\hline
\end{tabular}

Table 2. Changes in the fermentation parameters of the wort with $9{ }^{\circ} \mathrm{P}$ density (i.e., after the addition of $2.5 \%$ glucose) at $7{ }^{\circ} \mathrm{C}$ during $235 \mathrm{~h}$ of incubation.

\begin{tabular}{|c|c|c|c|c|c|c|c|c|c|}
\hline \multirow[b]{2}{*}{$\begin{array}{l}\text { Time } \\
\text { (h) }\end{array}$} & \multicolumn{3}{|c|}{ S. cerevisiae } & \multicolumn{3}{|c|}{ S. rouxii } & \multicolumn{3}{|c|}{ S. ludwigii } \\
\hline & $\begin{array}{c}\text { Density } \\
\left({ }^{\circ} \mathbf{P}\right)\end{array}$ & $\begin{array}{l}\text { Ethanol } \\
(\%, \mathrm{v} / \mathrm{v})\end{array}$ & pH & $\begin{array}{c}\text { Density } \\
\left({ }^{\circ} \mathbf{P}\right)\end{array}$ & $\begin{array}{l}\text { Ethanol } \\
(\%, v / v)\end{array}$ & pH & $\begin{array}{c}\text { Density } \\
\left({ }^{\circ} \mathbf{P}\right)\end{array}$ & $\begin{array}{l}\text { Ethanol } \\
(\%, v / v)\end{array}$ & pH \\
\hline 0 & $9.0 \pm 0.0$ & $0.0 \pm 0.00$ & $4.87 \pm 0.00$ & $9.0 \pm 0.0$ & $0.0 \pm 0.00$ & $4.87 \pm 0.00$ & $9.0 \pm 0.0$ & $0.0 \pm 0.00$ & $4.87 \pm 0.00$ \\
\hline 24 & $7.1 \pm 0.2$ & $1.6 \pm 0.11$ & $3.88 \pm 0.05$ & $7.0 \pm 0.2$ & $1.3 \pm 0.11$ & $3.85 \pm 0.03$ & $7.0 \pm 0.2$ & $0.8 \pm 0.8$ & $3.86 \pm 0.02$ \\
\hline 48 & $6.2 \pm 0.2$ & $2.6 \pm 0.09$ & $3.67 \pm 0.04$ & $6.5 \pm 0.4$ & $2.2 \pm 0.22$ & $3.68 \pm 0.04$ & $6.7 \pm 0.2$ & $1.5 \pm 0.09$ & $3.67 \pm 0.03$ \\
\hline 96 & $4.7 \pm 0.1$ & $3.0 \pm 0.08$ & $3.60 \pm 0.02$ & $4.7 \pm 0.4$ & $2.6 \pm 0.35$ & $3.62 \pm 0.05$ & $5.9 \pm 0.3$ & $1.7 \pm 0.05$ & $3.60 \pm 0.02$ \\
\hline 150 & $4.4 \pm 0.3$ & $3.6 \pm 0.14$ & $3.52 \pm 0.02$ & $4.2 \pm 0.5$ & $3.4 \pm 0.81$ & $3.52 \pm 0.05$ & $5.2 \pm 0.2$ & $2.1 \pm 0.06$ & $3.51 \pm 0.02$ \\
\hline 235 & $3.7 \pm 0.2$ & $4.1 \pm 0.15$ & $3.46 \pm 0.01$ & $3.5 \pm 0.5$ & $4.1 \pm 0.85$ & $3.47 \pm 0.02$ & $5.1 \pm 0.3$ & $2.8 \pm 0.05$ & $3.45 \pm 0.01$ \\
\hline
\end{tabular}




\section{Effects of strain type, glucose addition and temperature on the sugar consumption}

Profiles of sugar consumption during the fermentation periods for the three yeast strains are shown in Figures 2-5. When the original wort of brewery was used at $7^{\circ} \mathrm{C}$, almost all of the sugars were consumed equally by $S$. cerevisiae and $S$. rouxii but $S$. ludwigii consumed maltose more slowly when compared to the other two strains (Fig. 2). Addition of $2.5 \%$ glucose to the wort did not indicate any improvements on that aspect. Instead, maltose consumptions for the other two strains were also delayed due to the extra glucose available to these strains (Fig. 3). Apparently, glucose can be utilized by the yeast strains more readily than the other sugars. S. ludwigii is somewhat slower in the consumption of glucose when compared to the other two strains. When using the wort at its original conditions, glucose was consumed within $50 \mathrm{~h}$ of fermentation with $S$. cerevisiae and $S$. rouxii, while for $S$. ludwigii it took $100 \mathrm{~h}$ to finish the glucose. When $2.5 \%$ glucose was added to the wort, similar delay in the consumption of glucose was observed for S. ludwigii. For S. cerevisiae and $S$. rouxii, glucose was finished within $100 \mathrm{~h}$ of fermentation while for S. ludwigii, glucose was consumed over $150 \mathrm{~h}$ of fermentation (Figs. 2 and 3).

When using the wort at $12{ }^{\circ} \mathrm{C}$ at its original conditions, maltose consumption improved for all the three immobilized strains studied here and almost no difference was observed on that aspect among the three yeast strains (Fig. 4). However, the addition of $2.5 \%$ glucose at $12{ }^{\circ} \mathrm{C}$ resulted in a significant delay in the consumption of maltose for S. ludwigii (Fig. 5). Therefore, in absence of other sugars (at $12{ }^{\circ} \mathrm{C}$ ), S. ludwigii also could consume maltose. Such phenomenon could not occur at $7^{\circ} \mathrm{C}$

According to Fig. 2, maximum production of alcohol for all the three immobilized yeast strains was when they used glucose. During this phase, both $S$. rouxii and $S$. cerevisiae were faster than $S$. ludwigii in the consumption of glucose. When glucose was finished, $S$. rouxii started consuming ethanol as alternate source of carbon and as a consequence ethanol concentration was reduced in the wort. Such phenomenon did not occur in cases when $S$. cerevisiae and $S$. ludwigii were used. Instead, after glucose was fully consumed by these strains, the rate of alcohol production dropped accordingly (Fig. 2).

When additional glucose was present in the wort, ethanol concentration did not drop for any of the strains studied (Fig. $3)$, but as it happened in the previous case, the slope of ethanol production was reduced after glucose was fully consumed. At $12{ }^{\circ} \mathrm{C}$, similar behaviors were observed in the ethanol production except that $S$. rouxii started consuming part of the ethanol produced after glucose was finished in the wort at both densities studied (Figs. 4 and 5).

Results of this study indicated that all the three yeasts were immobilized successfully. Addition of $2.5 \%(\mathrm{w} / \mathrm{v})$ glucose proved the ability of alcohol production for all the immobilized yeast strains, but the greatest influence was observed with $S$. rouxii at $7{ }^{\circ} \mathrm{C}$ and also with both $S$. cerevisiae and S. ludwigii at $12{ }^{\circ} \mathrm{C}$. When temperature was increased from 7 to $12{ }^{\circ} \mathrm{C}$ the maximum effect was found with $S$. rouxii when the original wort of the brewery was used and in S. ludwigii when $2.5 \%(w / v)$ glucose was added to the wort.

When sugar consumption kinetics was investigated, it was discovered that the maximum influence of temperature was with S. ludwigii, when the original wort of the brewery was used because at $12{ }^{\circ} \mathrm{C}$ it could use maltose perfectly but not at $7{ }^{\circ} \mathrm{C}$.

Data showed that immobilization affected the cells physiology and metabolic activity, as also reported by other studies $(8,20)$. Free cells of $S$. ludwigii $(6,19)$ and $S$. rouxii (19) could not consume maltose (the most abundant sugar in the wort). Based on the current study, immobilized S. rouxii, in all cases and $S$. ludwigii, at $12^{\circ} \mathrm{C}$, could consume maltose. This may be due to the reduced intracellular $\mathrm{pH}$ values in the immobilized cells $(8,21)$ resulting in increased fermentation activities (productivity levels) of the enzymes. Indeed, the 
reduced intracellular $\mathrm{pH}$ was attributed to the increased permeability of cytoplasmatic membrane to protons (8), which led to a higher transport of some sugars such as maltose- $\mathrm{H}^{+}$, lactose- $\mathrm{H}^{+}$and hexose- $\mathrm{H}^{+}(5)$.

Although it was reported that $S$. rouxii is a weak alcohol producer (19), data from this study showed that the immobilized yeast were the highest producer of alcohol when compared with the two other yeast strains; i.e., S. cerevisiae and S. ludwigii. Such finding could be related to the ability of
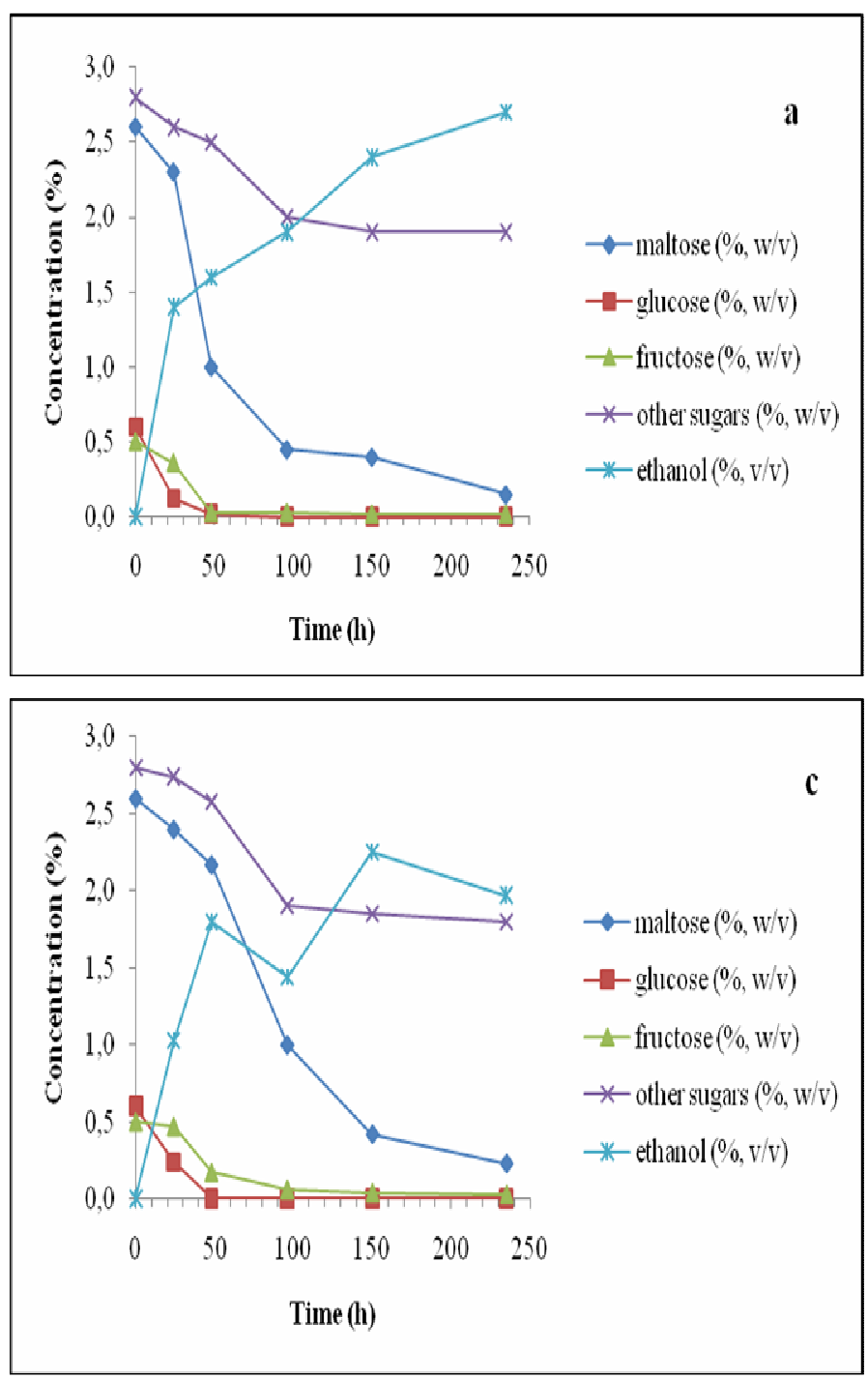

S. rouxii to consume maltose. It was reported that in the immobilized yeast increased the yield of glucose converted into ethanol $(8,14)$.

According to the results of this study, in order to make a beer with low ethanol concentration, S. ludwigii at low temperature and low density can be applied. On the other hand, S. rouxii at higher temperature and higher density of the wort can be applied for production of the high alcohol beer.

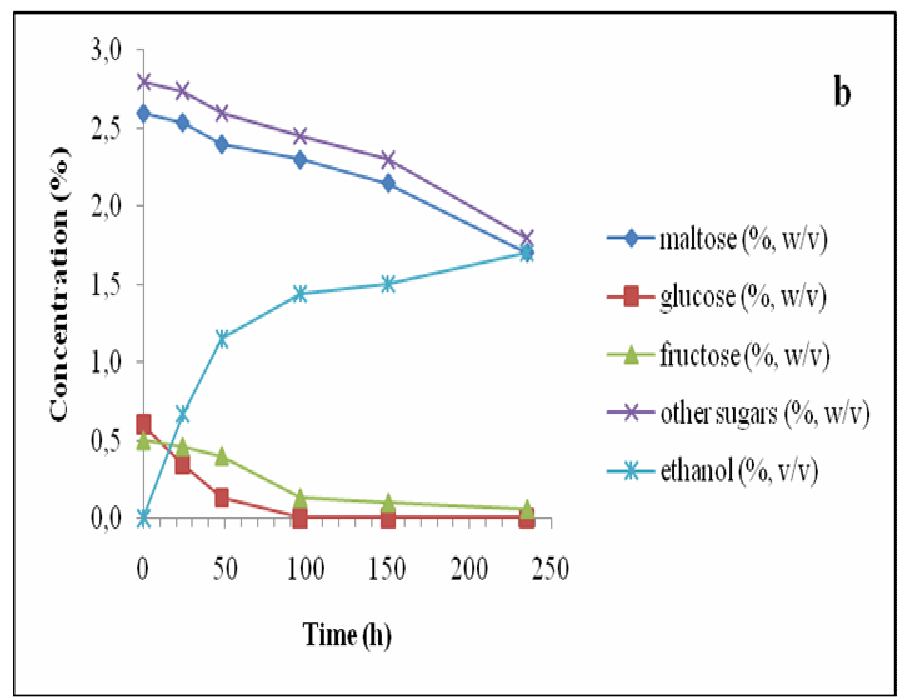

Figure 2. Changes in the concentrations of sugars and ethanol in the wort during $235 \mathrm{~h}$ of incubation with immobilized Saccharomyces cerevisiae (a), Saccharomyces ludwigii (b) and Saccharomyces rouxii (c) at $7{ }^{\circ} \mathrm{C}$ and $6.5^{\circ} \mathrm{P}$ density (i.e., the original wort density). 

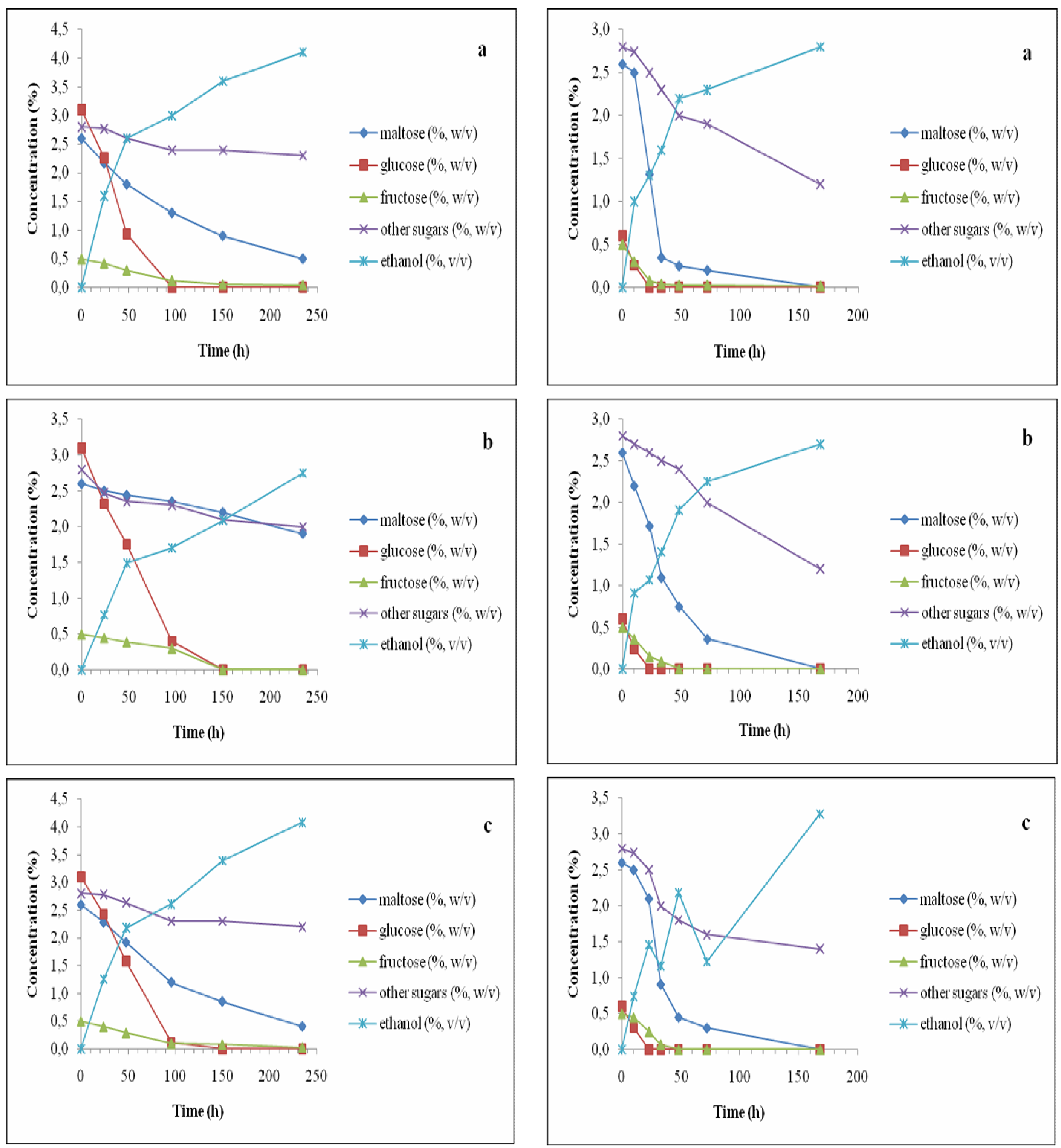

Figure 3. Changes in the concentrations of sugars and ethanol in the wort during $235 \mathrm{~h}$ of incubation with immobilized Saccharomyces cerevisiae (a), Saccharomyces ludwigii (b) and Saccharomyces rouxii (c) at $7{ }^{\circ} \mathrm{C}$ and $9{ }^{\circ} \mathrm{P}$ density (i.e., after the addition of $2.5 \%$ glucose).

Figure 4. Changes in the concentrations of sugars and ethanol in the wort during $168 \mathrm{~h}$ of incubation with immobilized Saccharomyces cerevisiae (a), Saccharomyces ludwigii (b) and Saccharomyces rouxii (c) at $12{ }^{\circ} \mathrm{C}$ and $6.5^{\circ} \mathrm{P}$ density (i.e., the original wort density). 

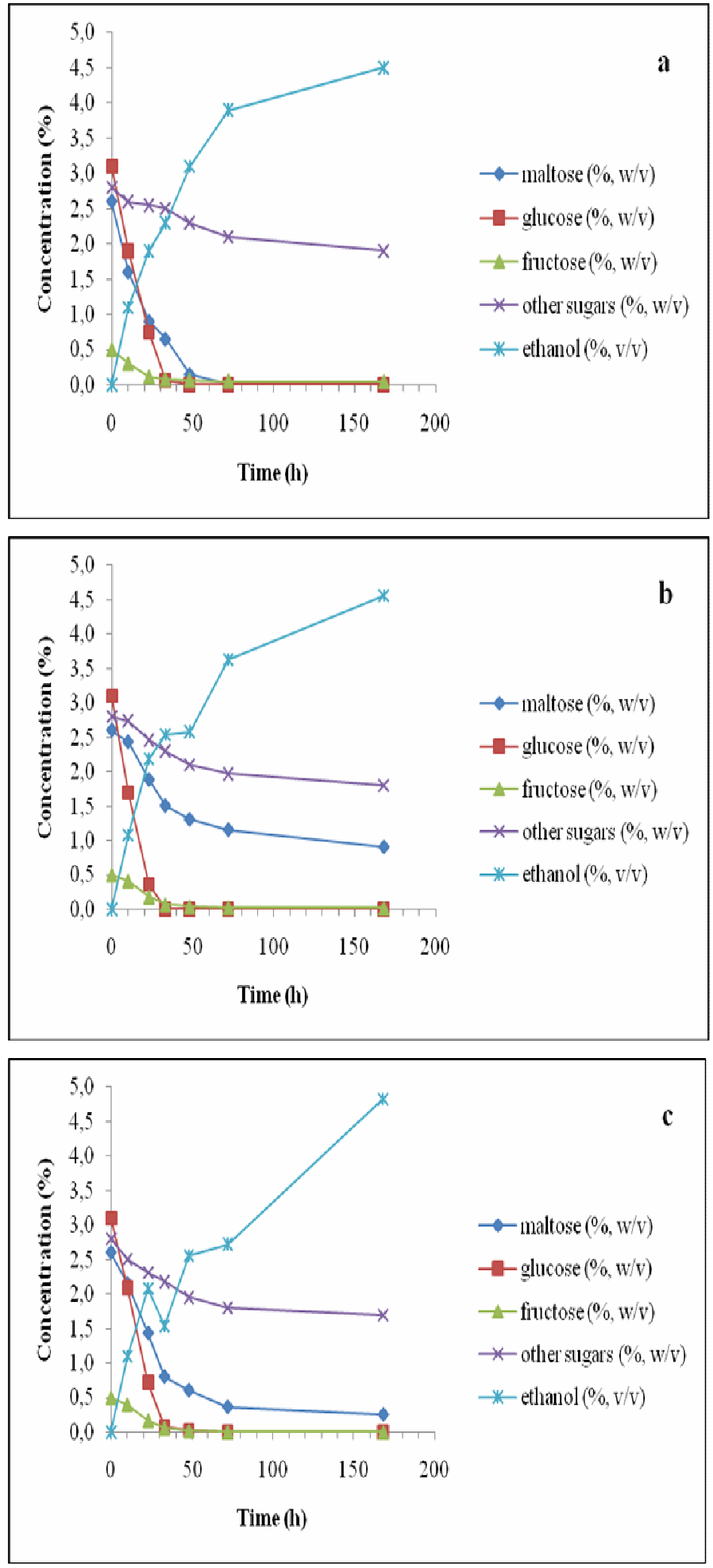

Figure 5. Changes in the concentrations of sugars and ethanol in the wort during $168 \mathrm{~h}$ of incubation with immobilized Saccharomyces cerevisiae (a), Saccharomyces ludwigii (b) and Saccharomyces rouxii (c) at $12{ }^{\circ} \mathrm{C}$ and $9{ }^{\circ} \mathrm{P}$ density (i.e., after the addition of $2.5 \%$ glucose).

\section{ACKNOWLEDGEMENTS}

The authors would like to thanks the "Research Council of the University of Tehran" and "Research Council at the campus of the Agricultural and Natural Resources of the University of Tehran" for financial assistance. Our gratitude also goes to ZamZam Corporation of Iran for its logistics help.

\section{REFERENCES}

1. Almeida, C.; Branyik, T.; Moradas-Ferreira, P.; Teixeira, J. (2003). Continuous production of pectinase by immobilized yeast cells on spent grains. J. Biosci. Bioeng., 96 (6), 513-518.

2. Athanasios, M.; Paul, L.; Argyro, B.; Athanasios, K.; Michael, K. (2007). Ambient and low temperature winemaking by immobilized cells on brewer's spent grains: Effect on volatile composition. Food Chem., 104, 918-927.

3. Bardi, E.; Koutinas, A.A.; Kanellaki, M. (1997). Room and low temperature brewing with yeast immobilized on gluten pellets. Proc. Biochem., 32 (8), 691-696.

4. Branyik, T.; Vicente, A.A.; Machado Cruz, J.M.; Teixeira, J.A. (2001). Spent grains - a new support for brewing yeast immobilization. Biotechnol. Lett., 23, 1073-1078.

5. Dickinson, J.R.; Kruckeberg, A.L. (2006). Carbohydrate Metabolism. In: Querol, A.; Fleet, G.H. (eds.). The Yeast handbook volume 2: Yeasts in food and beverages. Springer-Verlag, Berlin, Germany, p.215-242.

6. Fugelsang, K.C.; Edwards, C.G. (2007). Yeasts. In: Wine microbiology practical applications and procedures. 2nd ed. Springer Science+Business Media, New York, USA, p.3-14.

7. Fujii, N.; Sakurai, ededfdA.; Onjoh, K.; Sakakibara, M. (1999). Influence of surface characteristics of cellulose carriers on ethanol production by immobilized yeast cells. Proc. Biochem., 34, 147-152.

8. Kourkoutas, Y.; Bekatorou, A.; Banat, I.M.; Marchant, R.; Koutinas, A.A. (2004). Immobilization technologies and support materials suitable in alcohol beverages production: a review. Food Microbiol., 21, 377-397.

9. Kopsahelis, N.; Agouridis, N.; Bekatorou, A.; Kanellaki, M. (2007). Comparative study of spent grains and delignified spent grains as yeast supports for alcohol production from molasses. Bioresource Technol., 98, 1440-1447.

10. Kopsahelis, N.; Kanellaki, M.; Bekatorou, A. (2007). Low temperature brewing using cells immobilized on brewer's spent grains. Food Chem., 104, 480-488.

11. Lewis, M.J.; Bamforth, C.W. (2006). Yeast. In: Essays in brewing science. Springer Science+Business Media, New York, USA, p.114-130. 
12. Lewis, M.J.; Young, T.W. (1995). Brewing. 2nd ed. Chaoman \& Hall Publishing Inc., London, UK.

13. Nedovic, V.; Willaert, R.; Leskosek-Ukalovi, I.; Obradovi, B.; Bugarski, B. (2005). Beer production using immobilised cells. In: Hofman, M.; Anne, J.; Nedovic, V.; Willaert, R. (eds.). Applications of cell immobilisation biotechnology volume 8B: Focus on biotechnology. Springer, Netherlands, p.259-273.

14. Navarro, J.M.; Durand, G. (1977). Modification of yeast metabolism by immobilization onto porous glass. European J. Appl. Microbiol., 4, $243-$ 254.

15. Piskur, J.; Rozpedowska, E.; Polakova, S.; Merico, A.; Compagno, C. (2006). How did Saccharomyces evolve to become a good brewer?. Trends Genet., 22 (4), 183-186.

16. Pribylova, L.; Straub, M.L.; Sychrova, H.; Montigny, J. (2007). Characterisation of Zygosaccharomyces rouxii centromeresand construction of first $Z$. rouxii centromeric vectors. Chromosome Res., 15, 439-445.

17. Stradford, M. (2006). Food and beverage spoilage yeasts. In: Querol, A.; Fleet, G.H. (eds.). The Yeast handbook volume 2: Yeasts in food and beverages. Springer-Verlag, Berlin, Germany, p.336-379.
18. Romano, P.; Marchese, R.; Laurita, C.; Saleano, G.; Turbanti, L. (1999). Biotechnological suitability of Saccharomycodes ludwigii for fermented beverages. World J. Microbiol. Biotechnol., 15, 451-454.

19. Sohrabvandi, S. (2009). Study on effects of influencing factors on qualitative parameters of non-alcoholic beer produced by restricted fermentation practice. Tehran, Iran, 138p. (Ph.D. Thesis. University of Tehran).

20. Van Iersela, M.F.M.; Van Dieren, B.; Rombouts, F. M.; Abeea, T. (1999). Flavor formation and cell physiology during the production of alcohol-free beer with immobilized Saccharomyces cerevisiae. Enzyme Microb. Technol., 24, 407-411.

21. Van Iersel, M.F.M.; Brouwer-Post, E.; Rombouts, F.M.; Abee, T. (2000). Influence of yeast immobilization on fermentation and aldehyde reduction during the production of alcohol-free beer. Enzyme Microb. Technol., 26, 602-607.

22. Van Iersel, M.F.M.; Meersman, E.; Swinkels, W.; Abee, T.; Rombouts, F.M. (1995). Continuous production of non-alcohol beer by immobilized yeast at low temperature. J. Ind. Microbiol., 14, 495-501.

23. Yamazaki, T.; Oshima, Y. (1996). Saccharomycodes ludwigii has Seven Chromosomes. Yeast, 12, 237-240. 